\title{
Vuelta al cliché: Silvio Zavala positivista
}

\author{
Germán Luna Santiago* \\ Una vida dedicada al trabajo, como la que ha llevado Silvio Zavala, \\ ofrece muchas posibilidades de hallazgos afortunados y provechosos. \\ Andrés Lira
}

Es un lugar bastante común referir a Silvio Zavala como un historiador positivista. Y la adjetivación no es gratuita. Él mismo, en Los intereses particulares en la conquista de la Nueva España (1933) — su obra seminal-, expresaba con soltura el perfil rankeano de su pensamiento historiográfico: "Yo trato únicamente de decir, con apoyo en datos histórico-jurídicos, lo que hubo realmente. Por eso acudo al estudio objetivo de hechos". ${ }^{1}$ Que Zavala se asumiera así es algo muy comprensible si lo vemos desde su horizonte cultural: como para cualquier intelectual mexicano de su generación, Ranke confirmaba los ideales de la historia profesional desarrollada desde la segunda mitad del siglo XIX, es decir, aquella pretendidamente objetiva y científica. Comunicada a Zavala a través de su maestro Rafael Altamira y Crevea, la escuela de Ranke era asumida "como imagen emblemática del historiador que deseaba formarse". 2

Para la opinión general, a la postre, Zavala se convirtió inclusive en el paladín indiscutible del positivismo en México. Por eso, la controversia pública a la que Edmundo O'Gorman proponía a Zavala, en 1945, con motivo de la idea de verdad en la historia, cobró la más amplia relevancia: el joven O'Gorman se atrevía a cuestionar ni más ni menos que a la doxa anacrónica

* Maestro en Historiografía, Universidad Autónoma Metropolitana-Azcapotzalco, correo electrónico: germanls@yahoo.com.

1 Silvio Zavala, Los intereses particulares en la conquista de la Nueva España, 2a. ed., México, Instituto de Investigaciones Históricas, Universidad Nacional Autónoma de México, 1964, p. 12.

2 Guillermo Zermeño, "La historiografía en México: un balance (1940-2010)", Historia Mexicana, vol. LXII, núm. 4 [248], abril-junio, 2013, p. 1697. Véase Guillermo Zermeño, La cultura moderna de la historia. Una aproximación teórica e historiográfica, cap. 5, Centro de Estudios Históricos, El Colegio de México, México, 2002. 
reinante en el pensamiento histórico nacional. ${ }^{3}$ A propósito de la polémica suscitada entre el positivismo de Zavala y el historicismo de O'Gorman, se ha dicho que, con la supuesta declinación del primero a debatir públicamente sobre los problemas filosóficos del quehacer histórico, quedaba demostrada la victoria de la historia "filosófica", "el triunfo unánime de la nueva generación". ${ }^{4}$

La verdad es que Silvio Zavala no dejó de considerar el tema. En este análisis transcribo fragmentos selectos de dos entrevistas - hasta ahora desconocidasque fueron realizadas a Zavala a finales del siglo pasado. En ellas se comprueba que el historiador no fue sordo a las reflexiones historicistas. Aún más, revelan un cambio en su percepción histórica, pero a la vez una postura crítica. Estas fuentes sugieren que nuestro autor comprendía la imposibilidad de asumir que los documentos expresaban por sí solos la historia, tal como ésta había sido, y que el historiador se limitaba a comunicarla objetivamente por medio de su escrituración.

En una entrevista de 1982 - la cual nos es conocida—, Zavala admitía que, ciertamente, en sus años juveniles tenía la impresión de que los documentos hablaban por sí solos, que referían con voz propia el pasado. Pero señalaba que esta postura cambió con la madurez, pues poco a poco fue reconociendo que el relato histórico está necesariamente referido - por decirlo en los términos de Michel de Certeau - a un lugar social de producción situado en un tiempo y un espacio precisos: "Me daba cuenta de que cada generación viviente tiene sus ideas, sus sentimientos, sus convicciones, sus intereses, y que los proyecta [...] en ese pasado remoto [...]. Ya no veía tan pasivo al historiador en su función de receptor de los mensajes del pasado, sino que los contemplaba propiciando o estableciendo el diálogo de unas generaciones con otras, tomando y dando elementos en ese contacto". 5

Mi pesquisa en el Archivo Dr. Silvio Zavala, de la Biblioteca Nacional de Antropología e Historia, me informó de otra entrevista efectuada a Zavala en el mismo año, y publicada en la Gaceta UNAM el 27 de septiembre de 1982. Ahí, reitera cómo el historiador trabaja en función de un insumo esencial, el tiempo: "los problemas del tiempo — dice - son la tarea del historiador". Alude a una triple acepción temporal: el tiempo "personal", el "social" y el "ido". Le parece que este fenómeno debe tenerse en cuenta "para el trabajo del historiador":

3 En una entrevista, O’Gorman sintetizaba así su postura: "esa visión de la historia muy positivista [...] me parecía muy respetable, pero anticuada; [...] había que pensar otra historia, que se haga otras preguntas, que tenga otros intereses, otro punto de vista más filosófico, más relativista y no absoluto; sin las pretensiones del positivismo de poder presentar una visión de la historia como verdad absoluta". Teresa Rodríguez de Lecea, "Una entrevista con Edmundo O’Gorman”, en Historia Mexicana, vol. XLVI, núm. 4 [184], abril-junio, 1997, p. 959.

4 Abraham Moctezuma Franco, "El camino de la historia hacia su institucionalización", Historia y Grafía, núm. 25, 2005, p. 76.

5 Silvio Zavala, "Conversación sobre historia", Memoria de El Colegio Nacional, tomo X, núm. 1, 1982, p. 25. 
"Quizá, en última instancia, su tarea consista en la convergencia del tiempo personal y del tiempo social con esa tercera dimensión del tiempo ido, del tiempo pasado para incorporarlo a sus propias vivencias".

Pero, por otro lado, Zavala no dejaba de mostrar una justa reticencia hacia la historia filosófica. Consideraba que era demasiado su relativismo frente a la noción de verdad, como puede leerse en el fragmento de la segunda entrevista que aquí transcribo, aparecida en "El Búho" de Excelsior, el 10 de agosto de 1997: "entró en México, como en otras partes del mundo, el relativismo en la historia: la historia en realidad no es tal como ella ha existido sino como la vemos los de otras generaciones". En defensa de la idea contraria, de que sí existe una realidad histórica objetiva vivida por los hombres, Zavala se pregunta si habrá una mente sensata que pueda negar dos hechos del siglo, de suyo objetivos, en razón de haber sido experimentados por todos, a saber, la Guerra Civil Española y la Segunda Guerra Mundial: "Luego entonces - concluía Zavala - la historia no es cierto que la inventa quien la mira". Toda vez que estas opiniones fueron vertidas a los medios impresos, podemos preguntarnos si nos es legítimo afirmar que en Zavala cabía la censura contra la "adversaria" historia filosófica que venía a disputar el "monopolio" de la verdad histórica ${ }^{6}, \mathrm{y}$, asimismo, si podemos creer en la victoria de una escuela de pensamiento sobre otra.

A reserva de lo que se obtenga de un estudio más amplio y detenido, bajo la mirada del historicismo, el examen de la obra de don Silvio me dice que, en efecto, algunos de sus planteamientos no se sostienen en función de su mirada positivista. Pero ocurre exactamente igual en el sentido contrario. Esto puede ilustrarse con las discusiones que ha abierto Alfonso Mendiola - claro heredero de la escuela de O'Gorman - en torno a la lectura que hacemos en la actualidad de las crónicas de la Conquista. ${ }^{7}$ En primer lugar, admítase con Mendiola la naturaleza retórica de las crónicas: son fuentes que no hablan de la Conquista como una realidad histórica, en el sentido moderno de la expresión, sino de una realidad retórica, de una imagen en torno a la Conquista comprensible para el europeo de la época. De esta manera, las crónicas deben ser vistas como una representación más de las batallas entre las fuerzas del bien y del mal, como episodios bélicos mediante los cuales Dios expiaba los pecados de los hombres, pero no relatos periodísticos acerca de una confrontación "real". ${ }^{8}$ En rigor, para Mendiola, las crónicas "hablan más de la Europa de la época en que fueron escritas que del mundo americano",

6 Abraham Moctezuma Franco, op. cit., 2005, p. 44.

7 Alfonso Mendiola, Bernal Díaz del Castillo: verdad romanesca y verdad historiográfica, $2^{a}$. ed., México, Universidad Iberoamericana, 1995 y Retórica, comunicación y realidad. La construcción retórica de las batallas en las crónicas de la Conquista, Universidad Iberoamericana, México, 2003.

8 Alfonso Mendiola, op. cit., 2003, pp. 412-413. 
y, por lo tanto, no pueden ayudarnos a escribir la historia de la Conquista. ${ }^{9}$ A un supuesto semejante llegaba Luis Weckmann cuando indicaba las deudas que la historiografía colonial tiene con la del medievo: "su aceptación ciega de lo sobrenatural y de lo maravilloso", el ensalzamiento del heroísmo y la piedad, el tono de ejemplaridad y didactismo, la inserción de la Conquista en el sendero divino hacia la salvación; por ello, decía Weckmann, "muchos capítulos de la historia americana de aquel siglo no deben juzgarse como la historia de un hecho, sino como la presentación de una idea". ${ }^{10}$

En otro espacio ${ }^{11}$ he sugerido que, examinadas a partir de un tópico en particular, pero tan fundamental como el vasallaje indígena rememorado en las crónicas, las reflexiones de Mendiola son, en efecto, completamente reveladoras, pero al mismo tiempo que las representaciones que nos legaron las crónicas, no se comprenden del todo si ignoramos la realidad colonial objetiva como la que Silvio Zavala contribuyó a construir durante arduos años de trabajo. Tanto en las Cartas de relación de Cortés como en la Historia verdadera de su soldado medinés es posible leer ciertos rasgos de la ritualidad feudovasallática española. A propósito del vasallaje indígena, nuestros cronistas se empeñaron en retratar la actitud que le correspondería a los indígenas y a los españoles, de acuerdo con el código feudal: ayudar y obedecer a los delegados de su señor, en el caso de los primeros; proteger y honrar a los vasallos indígenas del rey, en el de los segundos. Es decir, en consonancia con la lectura de Mendiola, las crónicas evidencian una perfecta utilización de la retórica. Como comunicaciones escritas por y para europeos, destinadas a reproducir los códigos feudovasalláticos; como registro de las instituciones que regulaban entonces los vínculos entre los hombres en la sociedad española, las crónicas narran la Conquista desde aquello que la sociedad vencedora estaba dispuesta a creer. Las crónicas son, pues, un claro reflejo de lo que era natural decir y pensar en su tiempo. Ante esta evidencia, a propósito del vasallaje de Moctezuma, bien podríamos relativizar la creencia moderna de que "existió realmente" el acto de entrega del tlatoani en favor

del imperio español, según la lectura de los informes de Bernal Díaz del Castillo. ${ }^{12}$

Pero la relectura de estas fuentes sugiere algo más a propósito de la causa jurídica del vasallaje alardeado por nuestros cronistas. En las Cartas de relación, esta causa es la guerra o la imposición compulsiva del poder. Es decir, los naturales pactaron vasallaje porque experimentaron que la fuerza bélica hispana — que entraba a la tierra indígena dispuesta a "conquistar" -

10 Luis Weckmann, La herencia medieval de México, 2a. ed., El Colegio de México, Fondo de Cultura Económica, México, 1994, pp. 483-487.

11 Germán Luna Santiago, "Lo medieval en la Conquista: el problema del vasallaje indígena", en Relaciones. Estudios de Historia y Sociedad, vol. XL, núm. 158, 2019, en prensa.

12 Silvio Zavala, Las instituciones jurídicas en la conquista de América, núm. 13, 4a. ed., Porrúa, México, 2006, p. 27. 
era superior a la suya. En la Historia verdadera, por el contrario, el homenaje está sustentado por la entrega libre y verdadera de los indígenas con ocasión de su deseo de derrumbar a la tiranía azteca. ¿Cómo explicamos esta doble causa? ¿Lo atribuimos a la libre creación de historias "bonitas" a la que se dedicarían los cronistas para mejor provecho de sus ambiciones? ${ }^{13}$ Me parece que esto lo podemos resolver acudiendo no sólo a las funciones de la retórica, sino también al tiempo social — por emplear el vocabulario de Zavala- en el cual la retórica era ejercida. Este tiempo social sería el del mundo indiano del siglo XVI, un mundo marcado por el fenómeno jurídico, al cual hemos podido acceder gracias a trabajos como los de Zavala, y me estoy remitiendo en especial a su libro Las instituciones jurídicas en la conquista de América.

Leídas dentro de este tiempo social, las crónicas son también un reflejo de lo que podía y debía decirse en su época, pero en otro sentido: 1) que era lícito dominar al pagano por la vía bélica, tal como lo asume Cortés en sus cartas, en concordancia, por supuesto, con las teorías jurídicas de su tiempo sobre el título de primera ocupación proveniente del Derecho romano (toda tierra descubierta, junto a sus pobladores, decía ese título, se convertía de facto en la propiedad del descubridor), así como con la teoría del Ostiense de raigambre medieval, la cual admitía la potestad del Papado sobre los hombres, tanto espiritual como terrenalmente, lo cual lo facultaba para conceder o quitar tierras y señoríos a los príncipes cristianos, quienes por tanto podían exigir con todo derecho a todo hombre "donado" por gracia divina su sometimiento, y 2) que era lícito dominar al pagano sólo si por libre albedrío lo pedía, tal como lo asume Bernal Díaz del Castillo, en absoluta referencia al clima jurídico pactista de su tiempo, el cual le informaba a todo conquistador que su llegada a las Indias estaba justificada por una misión evangelizadora, no conquistadora, aunque podía adoptar este carácter en razón de algunas causas justas, como la presencia de un monarca tirano (nuestro Moctezuma): los reyes cristianos, decía Vitoria en esta dirección, se encontraban obligados a ayudar a los pueblos oprimidos e indefensos, procediendo incluso a la deposición de los señores tiranos. Reléase cómo explota nuestro Bernal la idea de un imperio opresor, como no lo hace Cortés, y se advertirá que, si bien mucho en su Historia verdadera podría pasar como una llana representación, como un cuadro repleto de bulos inventados por los cronistas, no es menos cierto que esta representación y estos bulos están totalmente referidos a una realidad objetiva, construida por y para nuestra mirada moderna o positivista si se quiere.

Un homenaje como el que ahora ofrecemos es acertado y generoso. Acertado porque — según lo entiendo al leer sus entrevistas — Zavala no estaba

13 Alguien ha dicho que en las crónicas "no hay nada verdadero a pesar de sus títulos"; la obra histórica producida en su época era "una bonita historia". "Analizan la realidad historiográfica de las crónicas indígenas sobre la conquista de México", Boletín INAH, núm. 146, 31 de mayo de 2016. 
cerrado a la reflexión, respetuosa y crítica, sobre el quehacer histórico que hoy sigue pareciéndonos fundamental para poder conducir nuestros esfuerzos, y generoso porque de esta manera reconocemos una intensa labor histórica que aún ilumina nuestras miradas sobre el pasado. Bien podemos concluir entonces con Andrés Lira que toda una vida dedicada al trabajo, como la de Silvio Zavala, siempre ofrecerá múltiples posibilidades de hallazgos afortunados y provechosos.

\section{EnTrevistas a Silvio Zavala}

\section{La tarea del historiador ${ }^{14}$}

Doctor ¿Cuál es el problema general de que trata un historiador?

"Se puede decir que tropezamos con el tiempo; los problemas del tiempo son la tarea del historiador. Está por una parte la vida de la persona, las transformaciones de su propio modo de ver las cosas. Al lado de este tiempo personal, está el paso del tiempo social, de la vida que se está desarrollando en torno de uno. Para acabar de complicar las cosas del tiempo del historiador, está el hecho de que su afición o profesión lo lanzan al tiempo ido, hacia otra gente que ya se ha pasado. Esta reflexión del tiempo hay que tenerla en cuenta para el trabajo del historiador. Quizá, en última instancia, su tarea consista en la convergencia del tiempo personal y del tiempo social con esa tercera dimensión del tiempo ido, del tiempo pasado para incorporarlo a sus propias vivencias".

A partir de 1975, el doctor Zavala se considera retirado. Piensa que no "se puede dar ninguna receta" en materia de líneas de investigación, "porque todo depende de la vocación y de las oportunidades de trabajo existentes; y después, de que la vida permita al investigador hacer aquello que se propone. Pero, eso sí, es necesario que exista un interés profundo o vocación por lo que se va a estudiar, una capacidad y preparación adecuadas para hacerlo bien, y después, que la vida permita una concentración fuerte para crear la obra. No debemos confundir los propósitos o las declaraciones con las obras que alcanzan realización; en estos temas, es la obra lo que cuenta, su importancia, su significación, sus méritos".

El doctor Zavala es leal a este punto de vista. Su retiro en verdad, es parcial. "Por mis viajes y mis trabajos anteriores, acumulé mucho material sobre mi disciplina. He creído que el uso mejor que podría hacer de lo que me queda de mi tiempo personal, es examinar esas fuentes que tengo acumuladas, formarme una impresión sobre ellas y transmitirla. He podido ya producir los volúmenes que tenía pendientes sobre historia sudamericana. Ahora estoy concentrándome en la historia de la Nueva España para comunicar todos esos elementos reunidos".

14 Fragmento de la entrevista publicada en la Gaceta UNAM, 27 de septiembre de 1982, p. 19, consultada en el Archivo Dr. Silvio Zavala de la Biblioteca Nacional de Antropología e Historia, Fondo: Hemerografía, Caja 73, exp. 2219. Se publicó también en El Sol de México, el 5 de octubre de 1982, sección D, p. 4. 
El historiador no puede callar la verdad ${ }^{15}$

En ocasiones escuchamos en programas de radio que el tiempo mexicano de hoy en día se puede comparar, digamos, con la época de los césares en Roma; la analogía es un nivel muy elemental de análisis por cuanto al discernimiento se refiere. Por eso pedimos al doctor Zavala que comente algo del método en Historia:

"Hay que tener cuidado con eso (los paralelismos)... El historiador y el tiempo están indisolublemente ligados. Yo digo que en ese enfoque noto el tiempo personal del historiador, cuándo nace y cuándo muere no lo escoge él, pero lo fija. No es lo mismo un historiador de hoy que un historiador del siglo xIX o del XVIII. El periodo de su vida lo marca, lo encuadra, digamos, porque su actividad y su mente funcionan de un tiempo a otro. En mi caso lo he visto muy cerca, por eso lo puedo entender: existe lo que yo llamo el tiempo social. Es decir, yo nací en 1909, me encuentro ya muy avanzado de edad, en este año de 1997 ya tengo 88 años de mi vida y 50 años dentro de El Colegio Nacional (el doctor ríe de manera franca al mencionar tal cantidad). En ese periodo me tocaron dos hechos de la historia de este siglo que fueron sumamente duros y que marcaron a las personas a quienes les tocó vivir en torno de esos hechos: la guerra Civil Española - yo estaba en España cuando empezó- y la Segunda Guerra Mundial que terminó en 1945.

"Y vea usted esto muy curioso que ha pasado: entró en México, como en otras partes del mundo, el relativismo en la historia: la historia en realidad no es tal como ella ha existido sino como la vemos los de otras generaciones. En México se exageró eso al punto de creer que la historia no existe y que lo único que existe es la visión del historiador que dice la historia fue esto, pero precisamente la guerra que termina en 1945 me trajo mucha luz sobre esta materia. Veamos: viene la contraofensiva aliada frente a los grandes poderes militares de los nazis de Alemania y de los fascistas de Italia; desde Inglaterra, tropas de Estados Unidos, de Canadá, y unas pocas de Francia que entonces estaba ocupada, llegan a Normandía. Fue una batalla terrible en costos, pero finalmente los aliados consiguen arraigar en la costa continental mientras los soviéticos descienden hacia Berlín; el mando alemán se ve perdido de Berlín y la guerra termina.

"Sin embargo, alguien ante hechos de este tipo puede replicar: no, ésa es tu visión de la historia en 1945, pero te voy a poner otra: los ejércitos de Alemania con sus aliados italianos cruzan el canal de La Mancha, conquistan Inglaterra, fusilan a Churchill y establecen el orden en el que Europa está viviendo desde aquel entonces. Quien pueda afirmar esto, sencillamente desconoce lo que se llama realidad histórica; y en ese punto nadie, nadie, puede tergiversar, ni engañar, ni mentir. Luego entonces la historia no es cierto que la inventa quien la mira. Ésta fue para mí una especie de luz que me daba la historia que estamos viviendo y que yo vi de cerca. Me aclaró muchísimo. Es lo que yo desde entonces llamo el diálogo entre el historiador y el tiempo que estudia.

15 Fragmento de la entrevista por Ricardo Pacheco Colín, publicada en "El Búho" de Excélsior, el 10 de agosto de 1997, pp. 1 y 6, consultada en la Hemeroteca Nacional, México, Fondo: Contemporáneo, Sección: Microfilmes. 
"Yo, por lo que acabo de explicar, soy muy exigente en cuanto el método de estudio, en cuanto al sentido de la historia, y a la responsabilidad del historiador; eso se ve mucho en mi vida y en mi obra, no son cosas que estoy inventando sino que las he vivido, y las defiendo y las sostengo; las sostengo con razones."

Entonces, el doctor Zavala repite de memoria lo dicho por Antonio de Herrera, el gran cronista de Indias en tiempos de Felipe II: "Yo he buscado las pruebas, me acerco a ellas, trato de establecer la verdad de los hechos que relato (...) una vez que creo haber visto la verdad, como historiador no puedo callar pon ningún motivo."

\section{Bibliografía}

Lira, Andrés, "Silvio Zavala, una jornada anterior", Historia Mexicana, vol. LXI, núm. 1 [241], julio-septiembre, 2011, pp. 275-288.

Luna Santiago, Germán, "Lo medieval en la Conquista: el problema del vasallaje indígena”, en Relaciones. Estudios de Historia y Sociedad, vol. XL, núm. 158, 2019, en prensa.

Mendiola, Alfonso, Retórica, comunicación y realidad. La construcción retórica de las batallas en las crónicas de la Conquista, México, Universidad Iberoamericana, 2003.

Mendiola, Alfonso, Bernal Díaz del Castillo: verdad romanesca y verdad historiográfica, 2a. ed., México, Universidad Iberoamericana, 1995.

Moctezuma Franco, Abraham, "El camino de la historia hacia su institucionalización", Historia y Grafía, núm. 25, 2005, pp. 45-78.

Rodríguez de Lecea, Teresa, "Una entrevista con Edmundo O’Gorman”, Historia Mexicana, vol. XLVI, núm. 4 [184], abril-junio, 1997, pp. 955-969.

Weckmann, Luis, La herencia medieval de México, 2a. ed., México, El Colegio de México, Fondo de Cultura Económica, 1994.

Zavala, Silvio, Las instituciones jurídicas en la conquista de América, 4a. ed., México, Porrúa, 2006.

, "Conversación sobre historia", Memoria de El Colegio Nacional, tomo X, núm. 1, 1982, pp. 13-28.

, Los intereses particulares en la conquista de la Nueva España, 2a. ed., México, Instituto de Investigaciones Históricas, Universidad Nacional Autónoma de México, 1964.

Zermeño, Guillermo, “La historiografía en México: un balance (1940-2010)”, Historia Mexicana, vol. LXII, núm. 4 [248], abril-junio, 2013, pp. 1695-1742.

, La cultura moderna de la historia. Una aproximación teórica e historiográfica, México, Centro de Estudios Históricos, El Colegio de México, 2002. 
Archivos

Archivo Dr. Silvio Zavala, Biblioteca Nacional de Antropología e Historia, México. Hemeroteca Nacional, México.

Hemerografía

Boletín INAH. 